\title{
Inversion for basal friction coefficients with a two-dimensional flow line model using Tikhonov regularization
}

\author{
Yuri V. Konovalov \\ Department of Mathematics, National Research Nuclear University MEPhl, Moscow, Russia
}

\begin{abstract}
We present results of basal friction coefficient inversion. The inversion was performed by a 2D flow line model for one of the four fast flowing ice streams on the southern side of the Academy of Sciences Ice Cap in the Komsomolets Island, Severnaya Zemlya archipelago. The input data for the performance of both the forward and the inverse problems included synthetic aperture radar interferometry ice surface velocities, ice surface elevations and ice thicknesses obtained by airborne measurements (all were taken from Dowdeswell et al., 2002). Numerical experiments with: i) different sea level shifts; and ii) randomly perturbed friction coefficient have been carried out in the forward problem. The impact of sea level changes on vertical distribution of horizontal velocity and on shear stress distribution near the ice front has been investigated in experiments with different sea level shifts. The experiments with randomly perturbed friction coefficient have revealed that the modeled surface velocity is weakly sensitive to the perturbations and, therefore, the inverse problem should be considered ill posed. To mitigate ill posedness of the inverse problem, Tikhonov's regularization was applied. The regularization parameter was determined from the relation of the discrepancy between observed and modeled velocities to the regularization parameter. The inversion was performed for both linear and non-linear sliding laws. The inverted spatial distributions of the basal friction coefficient are similar for both sliding laws. The similarity between these inverted distributions suggests that the changes in the friction coefficient are accompanied by appropriate water content variations at the glacier base.
\end{abstract}

Correspondence: Yuri V. Konovalov, Department of Mathematics, National Research Nuclear University MEPhI, Kashirskoe shosse, 31, Moscow, 115409, Russia.

E-mail: yu-v-k@yandex.ru

Key words: friction coefficient inversion, ice stream, 2D flow line model, Tikhonov's regularization method.

Acknowledgements: author is grateful to Prof. O.V. Nagornov and to Prof. A.S. Leonov for pre-discussion of the inverse problem developed in the manuscript. Author is grateful to Prof. J.A. Dowdeswell et al. for the data that have been used in the manuscript. Author is grateful to the Ministry of Education and Science of Russia (project no. P795).

Received for publication: 19 December 2011.

Revision received: 10 July 2012.

Accepted for publication: 10 July 2012.

This work is licensed under a Creative Commons Attribution NonCommercial 3.0 License (CC BY-NC 3.0).

(C) Copyright Y.V. Konovalov, 2012

Licensee PAGEPress, Italy

Research in Geophysics 2012; 2:e11

doi:10.4081/rg.2012.e11

\section{Introduction}

Observations based on digital Landsat imagery and on satellite synthetic aperture radar interferometry (InSAR) have revealed four drainage basins and four fast flowing ice streams respectively on the southern side of the Academy of Sciences Ice Cap, on the Komsomolets Island in Severnaya Zemlya archipelago (Figure 1). ${ }^{1}$ The four ice streams are between 17 and $37 \mathrm{~km}$ long and $4-8 \mathrm{~km}$ wide. ${ }^{1}$ Bedrock elevations of these areas are below sea level, and ice flow velocities reach values of 70-100 m/a (Figure 2). Such fast flow line features are typical for outlet glaciers and ice streams in both the Arctic and the Antarctic. These ice streams are the major locations of iceberg calving from the Academy of Sciences Ice Cap. ${ }^{1}$

The centerline geometry of one of the ice streams on the southern side of the Academy of Sciences Ice Cap is shown in Figure 3. Ice flow of this ice stream was simulated with a 2D flow line finite-difference model..$^{2,3}$ The model describes an ice flow along a flow line. ${ }^{2-4}$ The results of the modeling obtained for the $\mathrm{C}-\mathrm{C}$ ' flow line profile data (Figure 3 ) have shown that the ice surface velocity along the flow line reaches values of $100 \mathrm{~m} / \mathrm{a}$, assuming that ice experiences sliding. However, observed surface velocity distribution along C-C' flow line profile $^{1}$ could not be matched by the model experiments for constant values of friction coefficient and for both linear and non-linear friction laws. Absence of the good agreement between observed and modeled surface velocities suggests that the friction coefficient should be a spatially variable parameter. Therefore, to achieve a better agreement between observed and simulated velocities, the spatial distribution of the friction coefficients has to be optimized and an inverse problem needs to be solved..$^{5-11}$

In this manuscript, the inverse problem for basal friction coefficient distribution is considered and the results have been obtained for the $\mathrm{C}$ C' flow line profile (Figure 3).

Inversion for friction coefficients is based on minimization of the deviation between observed and modeled surface velocities. A series of test experiments, in which modeled surface velocities are used as observations in the inverse problem, have shown that the inverse problem for the full 2D ice flow line model is ill posed. More precisely, surface velocity is weakly sensitive to small perturbations in friction coefficients and, therefore, the perturbations appear in the inverted friction coefficients.

We present a solution to the ill-posed inversion problem based on the Tikhonov's regularization method, where Tikhonov's stabilizing functional was added to the main discrepancy functional. ${ }^{12}$ The regularization parameter was defined from the discrepancy versus regularization parameter relations. 


\section{Field equations}

\section{Forward problem}

\section{Basic equations}

The 2D flow line model used as a forward model in this study is similar to that developed by Pattyn ${ }^{2,3}$

$$
\left\{\begin{array}{l}
\int_{h_{b}}^{z} \frac{\partial u}{\partial x} d z^{\prime}+\frac{1}{b} \frac{d b}{d x} \int_{h_{b}}^{z} u d z^{\prime}+w-w_{b}=0 \\
2 \frac{\partial \sigma_{x x}^{\prime}}{\partial x}+\frac{\partial \sigma_{y y}^{\prime}}{\partial x}+\frac{\partial^{2}}{\partial x^{2}} \int_{z}^{h_{s}} \sigma_{x z}^{\prime} d z+\frac{\partial \sigma_{x z}^{\prime}}{\partial z}=\rho g \frac{\partial h_{s}}{\partial x} \\
\sigma_{i k}^{\prime}=2 \eta \dot{\varepsilon}_{i k} ; \quad \eta=\frac{1}{2}[A(T)]^{-\frac{1}{n}} \dot{\varepsilon}^{\frac{1-n}{n}} \\
0<x<L ; h_{b}(x)<z<h_{s}(x)
\end{array}\right.
$$

where $(x, z)$ is a rectangular coordinate system with the $x$ axis along the flow line and the $z$ axis pointing vertically upward; $u, w$ are horizontal and vertical ice flow velocities, respectively; $\sigma_{i k}, \sigma_{i k}$ are stress tensor and stress deviator, respectively; $\varepsilon_{i k}$ is strain-rate tensor; $\varepsilon$ is second invariant of the strain-rate tensor; $\eta$ is ice effective viscosity; $A(T)$ is flow-law rate factor; $T$ is ice temperature; $h_{b}(x), h_{s}(x)$ are ice bed and ice surface elevations, respectively; $L$ is the glacier length.

The continuity equation is rewritten in the integral form by integrat-

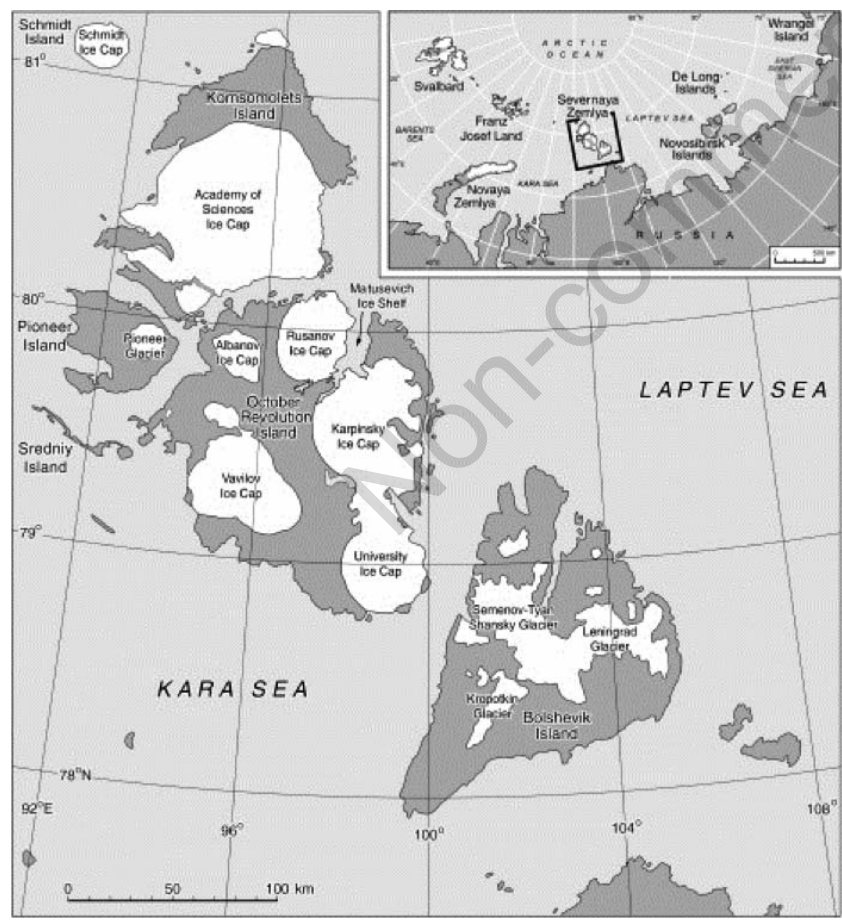

Figure 1 (after Dowdeswell et al. ${ }^{1}$ ). Map of Severnaya Zemlya showing the Academy of Sciences Ice Cap on Komsomolets Island together with the other ice caps in the archipelago: Rusanov Ice Cap, Vavilov Ice Cap, Karpinsky Ice Cap, University Ice Cap, Pioneer Glacier, Semenov-Tyan Shansky Glacier, Kropotkin Glacier, Leningrad Glacier. Inset is the location of Severnaya Zemlya and the nearby Russian Arctic archipelagos of Franz Josef Land and Novaya Zemlya within the Eurasian High Arctic.

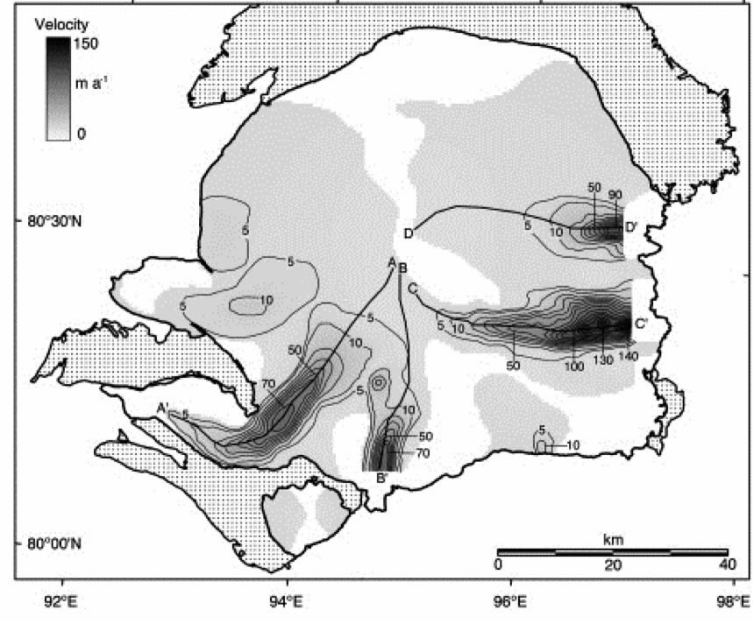

Figure 2 (after Dowdeswell et al. ${ }^{1}$ ). Corrected interferometrically derived ice surface velocities for the Academy of Sciences Ice Cap. The first two contours are at velocities of 5 and $10 \mathrm{~m} \mathrm{a}^{-1}$, with subsequent contours at $10 \mathrm{~m}$ a-1 intervals. Unshaded areas of the ice cap are regions of non-corrected velocity data. Dotted areas are bare land. The four fast flowing ice streams central lines are denoted as A-A', B-B', C-C', D-D' respectively. Velocity profiles A-A' to D-D' are shown in Figure 11 of Dowdeswell et al. In this manuscript the basal friction coefficient inversion for $\mathrm{C}^{-} \mathrm{C}^{\prime}$ flow line has been obtained.
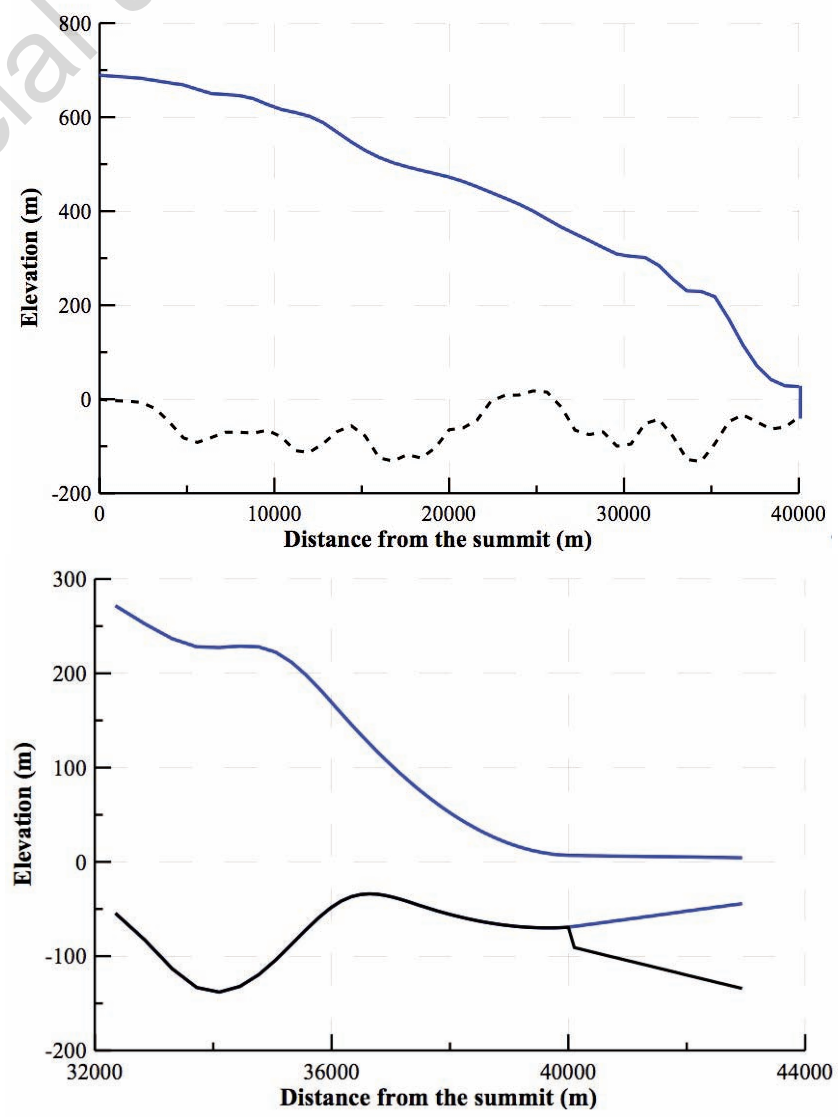

Figure 3. (A) The C-C' flow line profile, which crosses downstream one of the four fast flowing ice streams in the Academy of Sciences Ice Cap (Figure 2). The data of ice surface and ice bed elevations were imported from Figure 8 of Dowdeswell et al. ${ }^{1}$ (B) The ice shelf with trapezoidal geometry, which is considered as an extension of the $\mathrm{C}-\mathrm{C}^{\prime}$ profile. 
ing the differential continuity equation ${ }^{2,3}$ from $h_{b}$ to a current value of $z$. By combining the integral continuity equation with approximations of the boundary conditions at the ice front described below, the numerical solution stability of Eq. (1) is achieved.

The flow-law rate factor $A(T)$ was taken from Paterson. ${ }^{13}$ The description of constants and variables in the equations is provided in the Appendix.

\section{Boundary conditions}

The ice surface at $z=h_{s}$ is stress free. At the ice bottom $\left(z=h_{b}\right)$ ice is assumed to be sliding. Both linear and non-linear friction laws ${ }^{2,14-18}$ were considered. The general form of the friction law ${ }^{14,18}$ is expressed as:

$$
\tau_{i} \sigma_{i k} n_{k}=K_{f r}\left|\vec{v}_{b}\right|^{m-1}\left(\vec{v}_{b}\right)_{i} \tau_{i}
$$

where $K_{f r}$ is friction coefficient, $m$ is the exponent in the friction law, $m=1$ gives linear friction law and $m>1$ corresponds to non-linear friction law; $\vec{v}_{b}$ is the base ice flow velocity; $\vec{\tau}$ and $\vec{n}$ are tangential and normal to the bed vectors, respectively.

In accordance with basic equations of the model, the boundary conditions on the ice surface, at the glacier base (friction law) and at the ice shelf base can be rewritten in terms of stress deviator components.

The boundary conditions on the ice surface and at the ice shelf base can be written as

$\sigma_{x z}^{\prime}=\alpha_{s(b)}\left(2 \sigma_{x x}^{\prime}+\sigma_{y y}^{\prime}\right)$

where $\alpha_{s(b)}=\frac{\partial h_{s(b)}}{\partial x} /\left[1-\left(\frac{\partial h_{s(b)}}{\partial x}\right)^{2}\right]$.

The friction law (2) can be rewritten as

$$
\left\{\begin{array}{l}
\left(2 \sigma_{x x}^{\prime}+\sigma_{y y}^{\prime}\right) \frac{d h_{b}}{d x}-\sigma_{x x}^{\prime}\left(1-\left(\frac{d h_{b}}{d x}\right)^{2}\right)=-K_{f r}\left[u_{b}^{2}+w_{b}^{2}\right]^{\frac{m-1}{2}}\left(u_{b}+w_{b} \frac{d h_{b}}{d x}\right) \sqrt{1+\left(\frac{d h_{b}}{d x}\right)^{2}} ; \\
-u_{b} \frac{d h_{b}}{d x}+w_{b}=0 .
\end{array}\right.
$$

The inversion of friction coefficient for the non-linear Weertmantype friction law, which takes into account the basal slopes, was also performed for the C-C' profile. By considering two different sliding laws the effects of friction law formulation on the results of the inversion procedure were investigated.

The boundary conditions at the glacier terminus is normal stress exerted by sea water

$$
\left\{\begin{array}{l}
2 \sigma_{x x}^{\prime}+\sigma_{y y}^{\prime}+\frac{\partial}{\partial x} \int_{z}^{h_{s}} \sigma_{x z}^{\prime} d z=f(z) \\
\sigma_{x z}^{\prime}=0
\end{array}\right.
$$

where $f(z)=\left\{\begin{array}{l}\rho g\left(h_{s}-z\right), z>0 \\ \rho g h_{s}+\left(\rho_{w}-\rho\right) g z, z \leq 0\end{array}\right.$

and $\rho_{w}$ is the sea water density.

\section{Numerical solution and approximations of the bound- ary conditions}

The problem is solved numerically using the finite-difference method. ${ }^{2-4,19-23}$ The model considered so-called stretched coordinates, where vertical coordinate $\xi=\left(h_{s}-z\right) / H$ and is $0<\xi<1$.

To provide stability of the numerical solution, the boundary conditions have been included in the momentum equations [second equation from (1) $] \cdot .^{24,25}$ In particular, at the ice front boundary the combined momentum equation has the following form (in $x, \xi$ variables):

$$
\frac{\partial F}{\partial x}+\xi_{x}^{\prime} \frac{\partial F}{\partial \xi}-\frac{1}{H} \frac{\partial \sigma_{x z}^{\prime}}{\partial \xi}=\rho g \frac{d h_{s}}{d x}, \text { where }, F=2 \sigma_{x x}^{\prime}+\sigma_{y y}^{\prime}+\frac{\partial}{\partial x} \int_{z}^{h_{s}} \sigma_{x z}^{\prime} d z,
$$

and accounting for the boundary condition it becomes

$\frac{\partial F}{\partial x}+\xi_{x}^{\prime} \frac{\partial F}{\partial \xi}=\rho g \frac{d h_{s}}{d x},\left.\underline{\text { as }} \frac{\partial \sigma_{x z}^{\prime}}{\partial \xi}\right|_{x=L}=0$

and follows from (5).

Thus, taking into account the boundary conditions (5), the finite differencing in horizontal direction leads to the equation at $x=L$ :

$\frac{1}{\Delta x}\left\{2 \sigma_{x x}^{\prime}+\sigma_{y y}^{\prime}+\frac{\partial}{\partial x} \int_{z}^{h_{s}} \sigma_{x z}^{\prime} d z\right\}^{N_{x}-1} \approx-\rho g \frac{d h_{s}}{d x}+\frac{1}{\Delta x} f^{N_{x}}+\xi_{x}^{\prime}\left(\frac{\partial f}{\partial \xi}\right)^{N_{x}}$

Boundary condition at ice surface is written as

$$
\begin{aligned}
& 4\left(\frac{\partial \sigma_{x x}^{\prime}}{\partial x}\right)^{1}+4 \xi_{x}^{\prime}\left(\frac{\partial \sigma_{x x}^{\prime}}{\partial \xi}\right)^{1}+2\left(\frac{\partial \sigma_{y y}^{\prime}}{\partial x}\right)^{1}+2 \xi_{x}^{\prime}\left(\frac{\partial \sigma_{y y}^{\prime}}{\partial \xi}\right)^{1}+ \\
& +2 \xi_{x}^{\prime} \frac{\partial}{\partial x}\left(H \alpha_{s}\left(2 \sigma_{x x}^{\prime}+\sigma_{y y}^{\prime}\right)\right)^{1}+\left(\xi_{x x}^{\prime \prime}-\frac{1}{H} H_{x}^{\prime} \xi_{x}^{\prime}\right) H \alpha_{s}\left(2 \sigma_{x x}^{\prime}+\sigma_{y y}^{\prime}\right)^{1}+ \\
& +\left(\xi_{x}^{\prime 2}-\frac{1}{H^{2}}\right) \frac{1}{\Delta \xi}\left(\left(H \sigma_{x z}\right)^{2}-\alpha_{s} H\left(2 \sigma_{x x}^{\prime}+\sigma_{y y}^{\prime}\right)^{1}\right) \approx \rho g \frac{\partial h_{s}}{\partial x} ;
\end{aligned}
$$

where index 1 indicates that corresponding terms are approximated in grid nodes located at ice surface and index 2 corresponds to next subice-surface grid layer.

The continuity equation from Eq. (1) completes the full system of the boundary conditions at free surface and at the glacier terminus.

The boundary condition at the ice shelf base has the following form:

$4\left(\frac{\partial \sigma_{x x}^{\prime}}{\partial x}\right)^{N_{\xi}}+4 \xi_{x}^{\prime}\left(\frac{\partial \sigma_{x x}^{\prime}}{\partial \xi}\right)^{N_{\xi}}+2\left(\frac{\partial \sigma_{y y}^{\prime}}{\partial x}\right)^{N_{\xi}}+2 \xi_{x}^{\prime}\left(\frac{\partial \sigma_{y y}^{\prime}}{\partial \xi}\right)^{N_{\xi}}+$

$+2 \xi_{x}^{\prime} \frac{\partial}{\partial x}\left(H \alpha_{b}\left(2 \sigma_{x x}^{\prime}+\sigma_{y y}^{\prime}\right)\right)^{N_{\xi}}+\left(\xi_{x x}^{\prime \prime}-\frac{1}{H} H_{x}^{\prime} \xi_{x}^{\prime}\right) H \alpha_{b}\left(2 \sigma_{x x}^{\prime}+\sigma_{y y}^{\prime}\right)^{N_{\xi}}+$

$+\left(\xi_{x}^{\prime 2}-\frac{1}{H^{2}}\right) \frac{1}{\Delta \xi}\left(\alpha_{b} H\left(2 \sigma_{x x}^{\prime}+\sigma_{y y}^{\prime}\right)^{N_{\xi}}-\left(H \sigma_{x z}\right)^{N_{\xi}-1}\right)+$

$+\frac{\partial^{2}}{\partial x^{2}} \int_{0}^{\xi_{N \xi-1}} H \sigma_{x z} d \xi+\Delta \xi \frac{\partial^{2}}{\partial x^{2}}\left(\alpha_{b} H\left(2 \sigma_{x x}^{\prime}+\sigma_{y y}^{\prime}\right)^{N_{\xi}}\right) \approx \rho g \frac{\partial h_{s}}{\partial x} ;$

where index $N_{\xi}$ corresponds to grid layer located at the ice shelf base. The second equation, which completes the system of the boundary conditions at the ice shelf base, is $w_{b}=0$ [or in the general case $w_{b}=w(t)$ ]. This form of the second equation allows us to consider vertical deflections of the ice shelf.

\section{Inverse problem}

Inversion for the friction coefficient has been implemented using the gradient minimization procedure for the smoothed functional: ${ }^{12}$ 
$F=\int_{0}^{L}\left(u_{o b s}-u_{\text {mod }}\right)^{2} d x+\beta \int_{0}^{L}\left(K_{f r}{ }^{2}+q(x)\left(\frac{d K_{f r}}{d x}\right)^{2}\right) d x=\Phi+\Omega\left[K_{f r}\right]$,

where $u_{o b s}$ are observed velocities along the flow line and $u_{\text {mod }}$ are modeled velocities; $\Phi$ denotes the first integral and $\Omega$ is the stabilizer, ${ }^{12} \beta$ is the regularization parameter; and $q(x)$ was considered equal to 1 . The non-zero value of $\beta$ implies that the inverse problem, i.e. the problem, which is based on the minimization of the discrepancy $\Phi$, is ill posed and the original problem of the discrepancy minimization is replaced with the problem of the smoothed functional (9) minimization. The minimization has been performed using the gradient minimization procedure ${ }^{26}$ which is written as an iterative sequence of the friction coefficient values in the grid nodes:

$$
\left(K_{f r}\right)_{i}^{m+1}=\left(K_{f r}\right)_{i}^{m}-\gamma_{i}^{m} \frac{\partial F^{m}}{\partial\left(K_{f r}\right)_{i}}, \quad \gamma_{i}^{m} \sim \frac{\gamma_{0} / m^{p}}{\max _{1 \leq i \leq N_{x}}\left|\frac{\partial F^{m}}{\partial\left(K_{f r}\right)_{i}}\right|}, p>0
$$

where $\left(K_{f r}\right)^{m}$ are the friction coefficient values in the grid nodes at the $m$ the step of the iterative sequence; $y_{i}^{m}$ is the parameter of the gradient minimization procedure.

The gradient of $\Phi$, which is a part of the gradient in Eq. (10), is defined as

$$
\frac{\partial \Phi^{m}}{\partial\left(K_{f r}\right)_{i}}=-2 \int_{0}^{L}\left(u_{\mathrm{obs}}-u_{\mathrm{mod}}^{m}\right) \frac{\partial u_{\mathrm{mod}}^{m}}{\partial\left(K_{f r}\right)_{i}} d x
$$

where

$$
\frac{\partial u_{\max }^{m}}{\partial\left(K_{f r}\right)_{i}} \approx \frac{u_{\operatorname{mad}}^{m}\left(\left(K_{f r}\right)_{1} \ldots,\left(K_{f r}\right)_{i}+\Delta\left(K_{f r}\right)_{i}, . .\left(K_{f r}\right)_{N_{x}}\right)-u_{\text {med }}^{m}\left(\left(K_{f r}\right)_{1} \ldots,\left(K_{f r}\right)_{i}-\Delta\left(K_{f r}\right), \ldots\left(K_{f r}\right)_{N_{x}}\right)}{2 \Delta\left(K_{f r}\right)_{i}}
$$

is the derivative calculated numerically using the forward model that runs for the two friction coefficient distributions

(i) $\left(K_{f r}\right)_{1} . .,\left(K_{f r}\right)_{i}+\Delta\left(K_{f r}\right)_{i} . .\left(K_{f r}\right)_{N x}$ and (ii) $\left(K_{f r}\right)_{1} . .,\left(K_{f r}\right)_{i}-\Delta\left(K_{f r}\right)_{i} . .\left(K_{f r}\right)_{N x}$.

\section{Numerical experiments}

\section{Forward problem}

The numerical experiment performed with randomly perturbed friction coefficient (Figure 4A) has shown that the sensitivity of the horizontal surface velocity to the amplitude of the random perturbations is relatively low (Figure 4B).

The initial friction coefficient distribution was taken in the form of a smoothed step function (Figure 4A). The random perturbations of the friction coefficient at $x>L / 2$ (the random perturbations of the lower level of the friction coefficient value) show insignificant ice surface velocity changes (Figure 4C). The dependence, which is the surface velocity deviation versus the amplitude of the perturbations (Figure $4 \mathrm{C}$ ), proves that $10 \%$ uncertainty in the surface velocity makes all perturbed friction coefficient distributions equivalent. This uncertainty can be found in observed data or, in particular, can result from the approximate ice temperature distribution assigned in the model. In other words, if the uncertainty in the horizontal surface velocities is approximately $10 \%$, we cannot choose any friction coefficient distribution from a bulk of the randomly perturbed coefficients (Figure 4A).

The next experiment, which was performed with various ice shelf
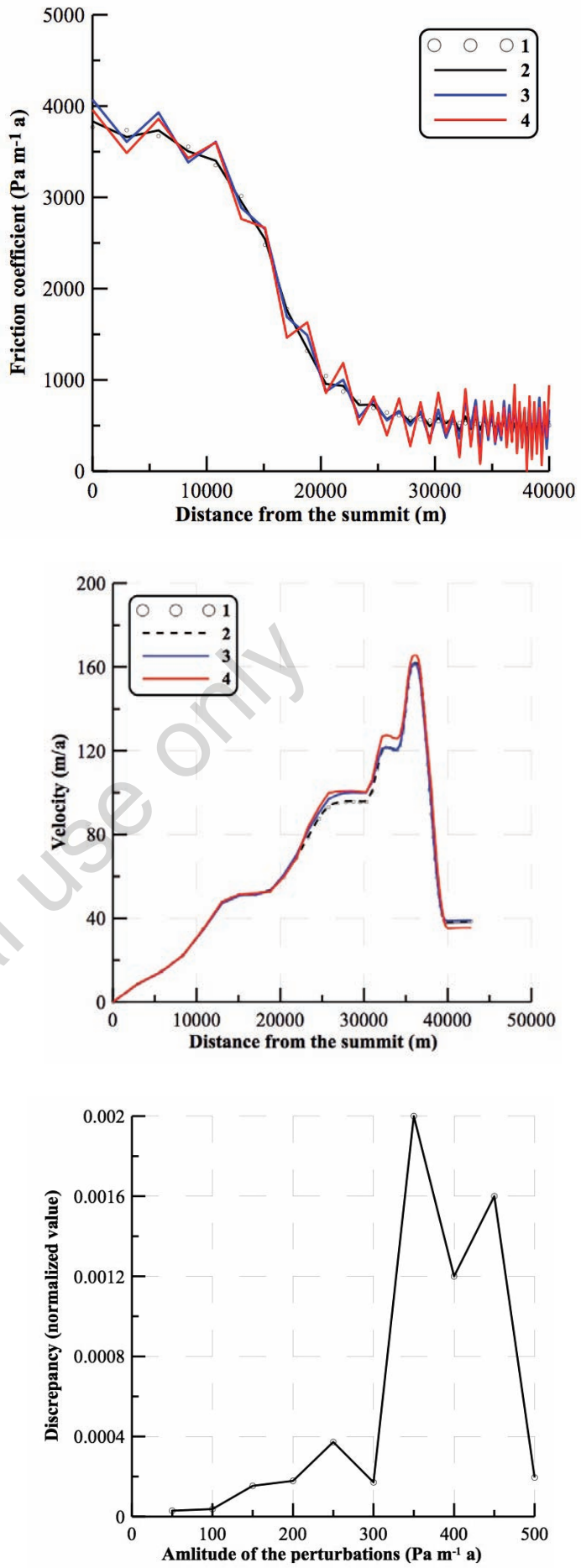

Figure 4. (A) The friction coefficient distributions along the flow line. 1 - initial friction coefficient distribution. 2-4 - randomly perturbed friction coefficient distributions with different amplitudes of the perturbations $\Delta K_{f .} 2-\Delta K_{f r}=10^{2} \mathrm{~Pa} \mathrm{~m} \mathrm{~m}^{-1} \mathrm{a} .3$ $\Delta K_{f:}=3.10^{2} \mathrm{~Pa} \mathrm{~m}^{-1} \mathrm{a} .4-\Delta K_{f:}=5.102 \mathrm{~Pa} \mathrm{~m}^{-1} \mathrm{a}$. (B) The ice surface horizontal velocity distributions that correspond to the friction coefficient distributions, are represented in Figure 4A. (C) The discrepancy between ice surface horizontal velocity distributions obtained for the initial friction coefficient distribution (curve 1 in Figure 4A) and randomly perturbed friction coefficient distribution. The perturbations were applied to the lower level of the step function, which defines the initial friction coefficient distribution. The figure exemplifies that, generally, the ice surface velocity deviation doesn't increase despite the enhancement of the deviation in friction coefficient distributions - the deviation is defined as $\operatorname{maz} 0<\mathrm{z}<\mathrm{L}\left|\mathrm{K}_{\mathrm{fr} 1}(x)-K_{\mathrm{fr} 2}(x)\right|$. 
lengths, shows that the modeled surface velocity distribution remains practically unchanged if the ice front is removed to the coastal ice margin (Figure 3A). The relative deviation in the modeled surface velocities that have been obtained both with (Figure 3B) and without (Figure $3 \mathrm{~A})$ the ice shelf, respectively, is approximately $6 \%$, depending on the grid size. This result is interesting from a computational point of view. The inverse problem requires $2 N_{x G l}$ runs of the forward problem at each step of the gradient minimization procedure $\left(2 N_{x G l}\right.$ is the number of horizontal grid nodes in the glacier vertical cross-section) (Figure 3A).

A third experiment performed with different sea level shifts shows that horizontal ice flow velocity is sensitive to sea level changes (Figure 5); glacier terminus position corresponds to the coastal ice margin. Depth averaged horizontal velocity and horizontal velocity profile at the glacier terminus (ice sheet front) are both sensitive to sea level changes (Figure 5). The 10-m sea level shift leads to an approximate $30 \%$ increase in the depth-averaged velocity at the terminus. The horizontal velocity maximum at the terminus is located at the sea level and this maximum is reinforced when the sea level drops (Figure 5).

The simulated vertical distribution of the horizontal velocity can be used to calculate stresses near the terminus. The 10 -m sea level changes are accompanied by an approximate doubling of the shear stress (Figure 6). The results imply that the periodically (diurnally) shear stress changes can lead to ice breaking and to the calving of small debris at the ice front. Indeed, the zone of drastic stress changes can be considered as the zone of crevasses. The known calving models are based on the ice surface crevasses propagation. ${ }^{27}$ Additionally, an increase in the longitudinal stresses due to a drop in sea level should decrease the threshold value of shear stress for the appearance of crevasses. Thus, the extent of the crevasse zone (from the terminus inward to the glacier) could be estimated from the extent of the zone where stresses experience large variations due to changes in sea level. In particular, this is approximately $10-15 \mathrm{~m}$ for $l=10 \mathrm{~m}$ in the model and, thus, the maximum width of ice debris can be assessed to be approximately $10 \mathrm{~m}$.

It should be noted that, usually, diurnal sea level changes are much less than $10 \mathrm{~m}^{28}$ and the main mechanisms that trigger ice calving are associated with the impact of the ocean swells on the ice front ${ }^{29}$ and on seismic ice quake..$^{30}$ Nevertheless, there are regions on the Earth where diurnal changes in water level can reach approximately $10 \mathrm{~m}$. For example, an approximate $15 \mathrm{~m}$ change in diurnal water level is observed in the lake which washes the terminus of Glacier Perito Moreno in Patagonia. ${ }^{31}$ The borehole measurements at the Glacier Perito Moreno have shown that the water levels in the boreholes were oscillating in a diurnal manner within a range of $\pm 15 \mathrm{~m}^{31}$

\section{Inverse problem}

Inversion for friction coefficient has been tested with artificial observed surface velocities. The spatial distribution of the observed surface velocity has been obtained for a given friction coefficient distribution. The inversions were performed using a smoothed step function as a given spatial distribution of friction coefficients (Figure 7). The discrepancy depends on the regularization parameter (Figure 8).

To account for the dependence of the ice viscosity on temperature, it is assumed that the vertical temperature distribution is linear. In addition, it is assumed that the ice temperature linearly increases from $15^{\circ} \mathrm{C}$ at the surface to $-5^{\circ} \mathrm{C}$ at the ice base at the divide, and increases from $-2^{\circ} \mathrm{C}$ to $-1^{\circ} \mathrm{C}$ at the margin. The reconstructed friction coefficients gradually decrease from approximately $3.5 \cdot 10^{3} \mathrm{~Pa} \mathrm{a} \mathrm{m}^{-1}$ to a mean value of $5 \cdot 10^{2} \mathrm{~Pa} \mathrm{a} \mathrm{m}^{-1}$ achieved around $25<x<40 \mathrm{~km}$ (Figure 9A). The mismatch between simulated and observed surface velocities is relatively small (Figure 9B).

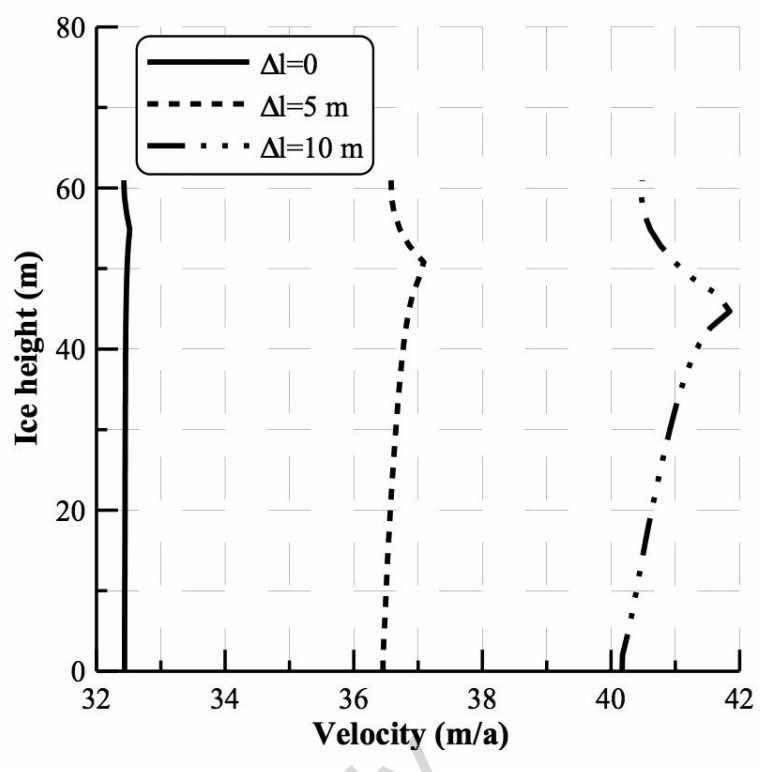

Figure 5. Horizontal velocity profiles at the ice front obtained for different sea level shifts $(\Delta \mathrm{l}) \cdot \Delta l=0$ corresponds to floating ice, i.e. $-\boldsymbol{b}_{\mathrm{b}} \rho_{\mathrm{w}}=\left(\boldsymbol{h}_{s}-\boldsymbol{b}_{b}\right) \rho$ where $\rho_{w}$ is sea water density.

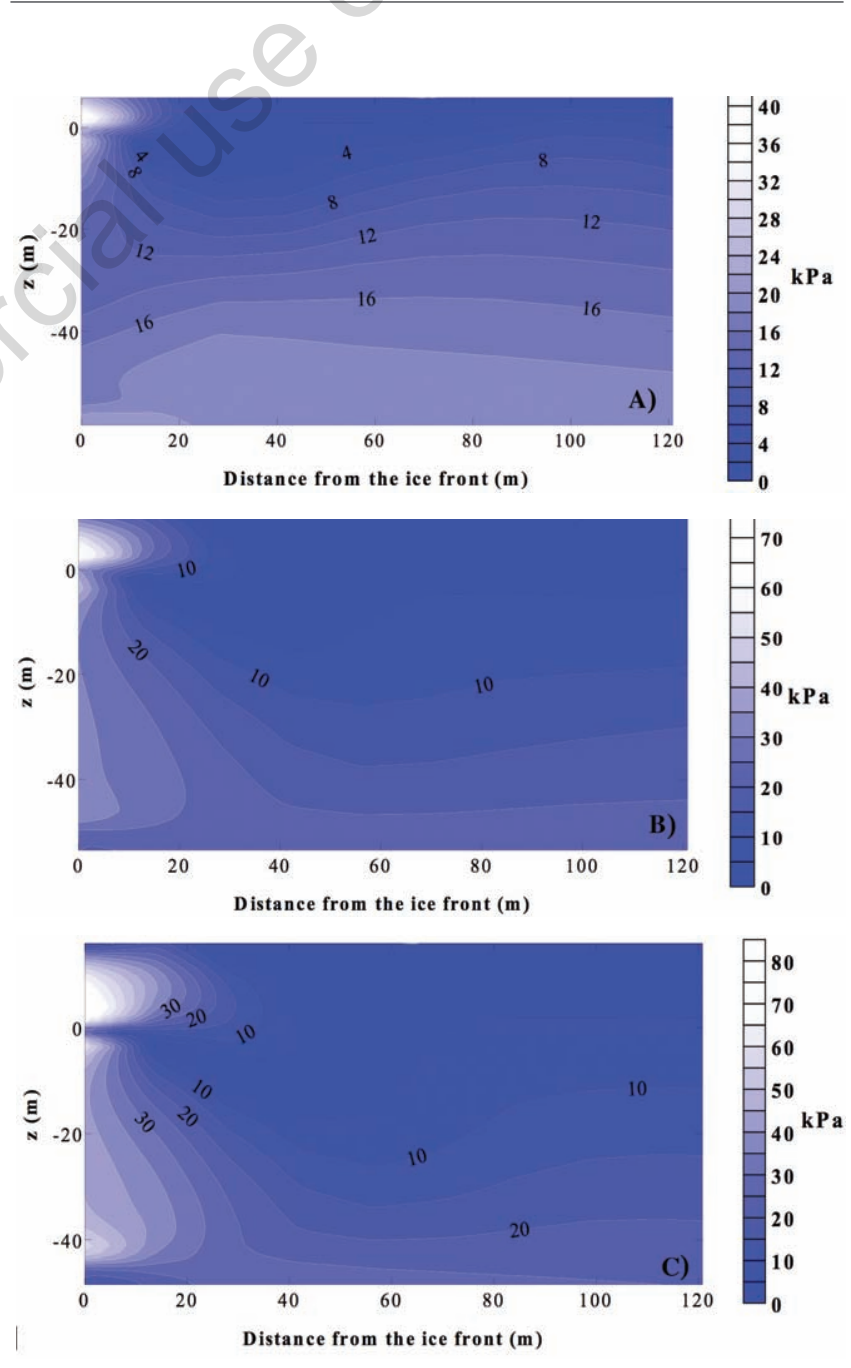

Figure 6. Shear stress (absolute values) distributions in the ice front vicinity obtained for different sea level shifts: A) $\Delta l=0$; B) $\Delta l=5 \mathrm{~m}$; C) $\Delta l=10 \mathrm{~m}$. 


\section{Discussion}

Numerical experiments with the randomly perturbed friction coefficient have revealed that the horizontal surface velocity is weakly sensitive to the perturbations and, thus, the perturbations appear on the $x$ distribution of the inverted friction coefficient. Therefore, the inverse problem should be considered as ill posed because the weak sensitivity of the surface velocity to the perturbations in the friction coefficient signifies inverse problem instability. Otherwise, the instability in the inverse problem means that small deviations in observed surface velocities allow sufficient perturbations in the friction coefficient. Hence, the application of the regularization method is substantiated.

Tikhonov's stabilizing functional method reduces the effects of perturbations proportionally to the regularization parameter $\beta$. Further increase in the parameter leads to a reduction in the real spatial variability of the friction coefficients.

The reduction in the existent friction coefficient variability is accompanied by a growing discrepancy between observed and modeled surface velocities (Figure 8). Thus, the regularization parameter is
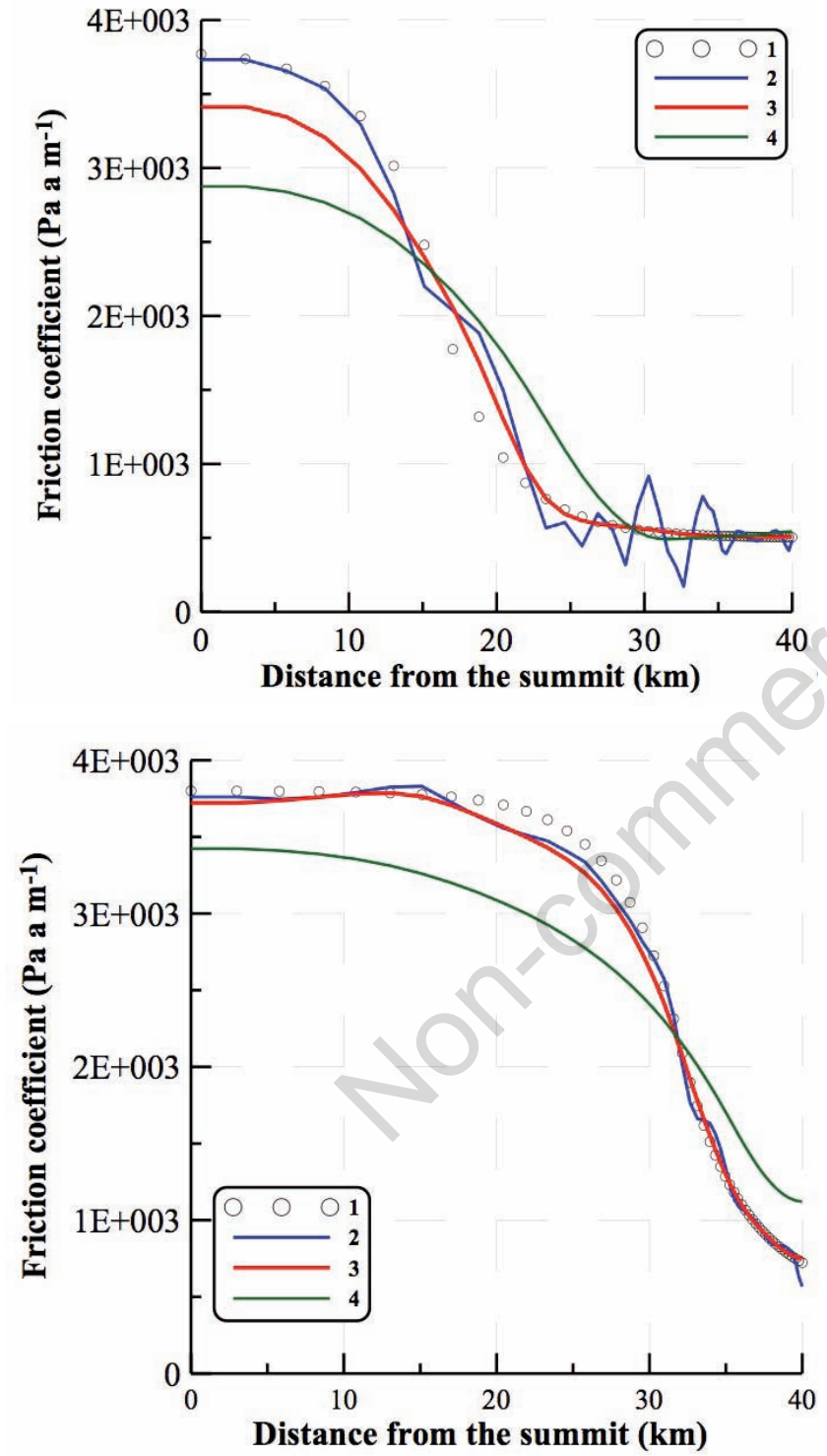

Figure 7. Friction coefficient distributions obtained in the test inverse problem, in which the modeled surface velocities obtained in the forward problem are used in Eq. (9) instead of observed surface velocities. 1 - initial friction coefficient distribution was taken in the form of the smoothed step function, which gradually drops from a maximum value $K_{1}$ to a minimum value $K_{2} .2-4-$ reconstructed friction coefficient distributions: $2-\beta=2 \cdot 10^{-7}, 3$ $\beta=10^{-4}, 4-\beta=8 \cdot 10^{-4}$. The inversions shown in figures (A) and (B) differ in the initial friction coefficient distributions.
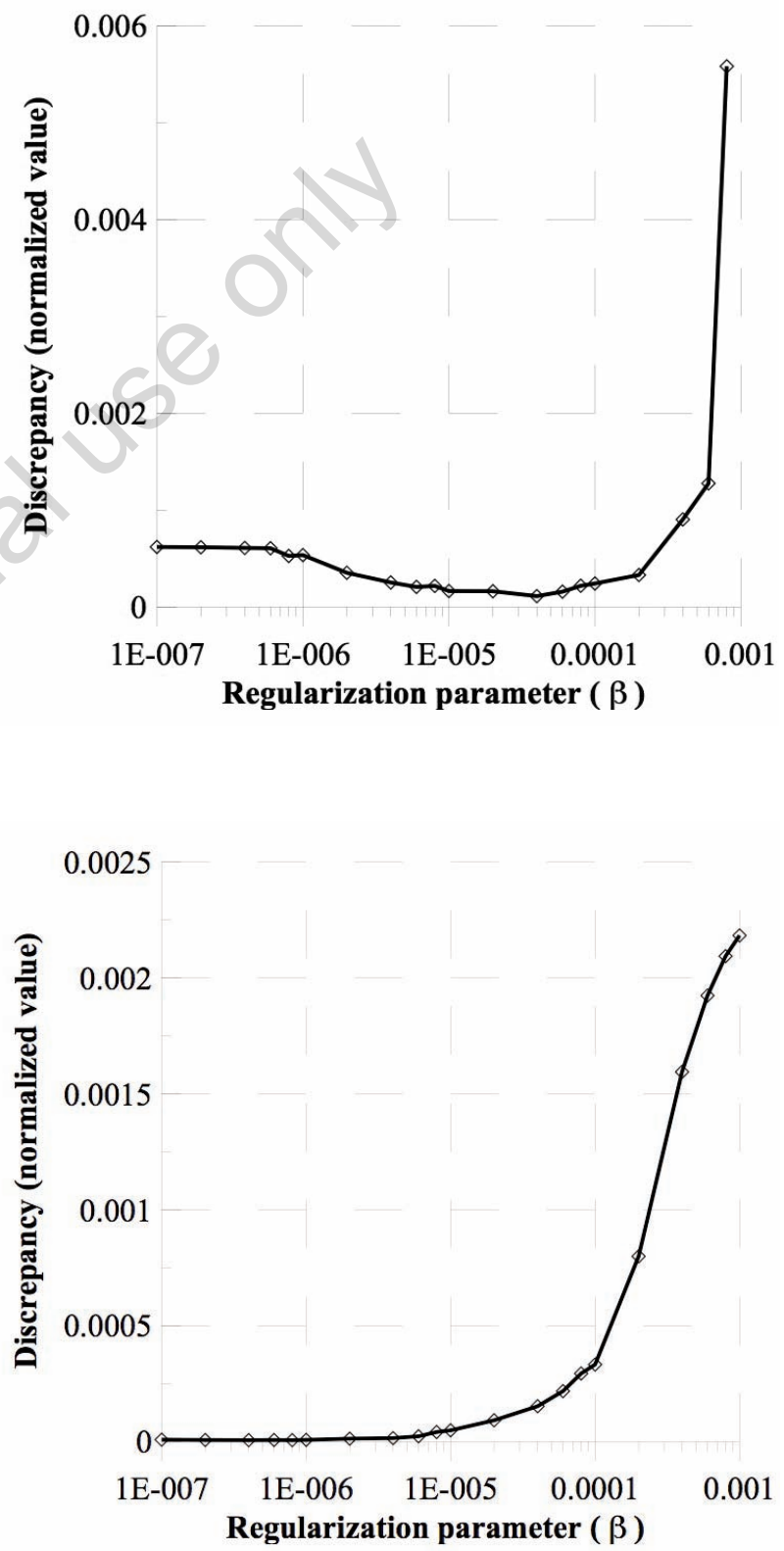

Figure 8. Discrepancy functional values versus regularization parameter in the test inverse problems. Figure (A) corresponds to the friction coefficient distributions represented in Figure $7 \mathrm{~A}$ and figure (B) corresponds to the friction coefficient distributions represented in Figure $7 \mathrm{~B}$. 
chosen as the value at which non-existent perturbations have been reduced but the real variability of friction coefficient is not fully smoothed. The optimal value of the regularization parameter can be defined approximately in the curve which is the deviation between observed and modeled surface velocities versus the regularization parameter (Figure 8). This method of selecting the optimal regularization parameter was theoretically validated in Leonov. ${ }^{32}$

Evidently, application of Tikhonov's regularization method narrows a range of possible inverted $x$-distributions of the friction coefficients. Thus, it is supposed a priori that real $x$-distribution of friction coefficient is a smooth function. Furthermore, the friction coefficients in the friction laws are constants. ${ }^{2,15-17}$ Hence, the friction coefficient inver- sion performed for the C-C' cross-section (Figure 9A) can be interpreted as follows: a large value of the friction coefficient at $0<x<20 \mathrm{~km}$ apparently means that ice is frozen to the bed at this distance from the summit. Then, it seems the basal temperature can reach the melt point at $25<x<40 \mathrm{~km}$ due to an increase in both deformational heating and ice surface temperature and, thus, the basal sliding appears at $x>25$ $\mathrm{km}$. Otherwise, the water presence in the basal layer can be explained by the low bed elevations in the areas of fast flowing ice streams. The water presence in the basal layer provides the basal sliding which will in due time increase basal temperature from the basal friction in the appropriate areas of ice base.

General formulations of the friction laws suppose that the appropri-
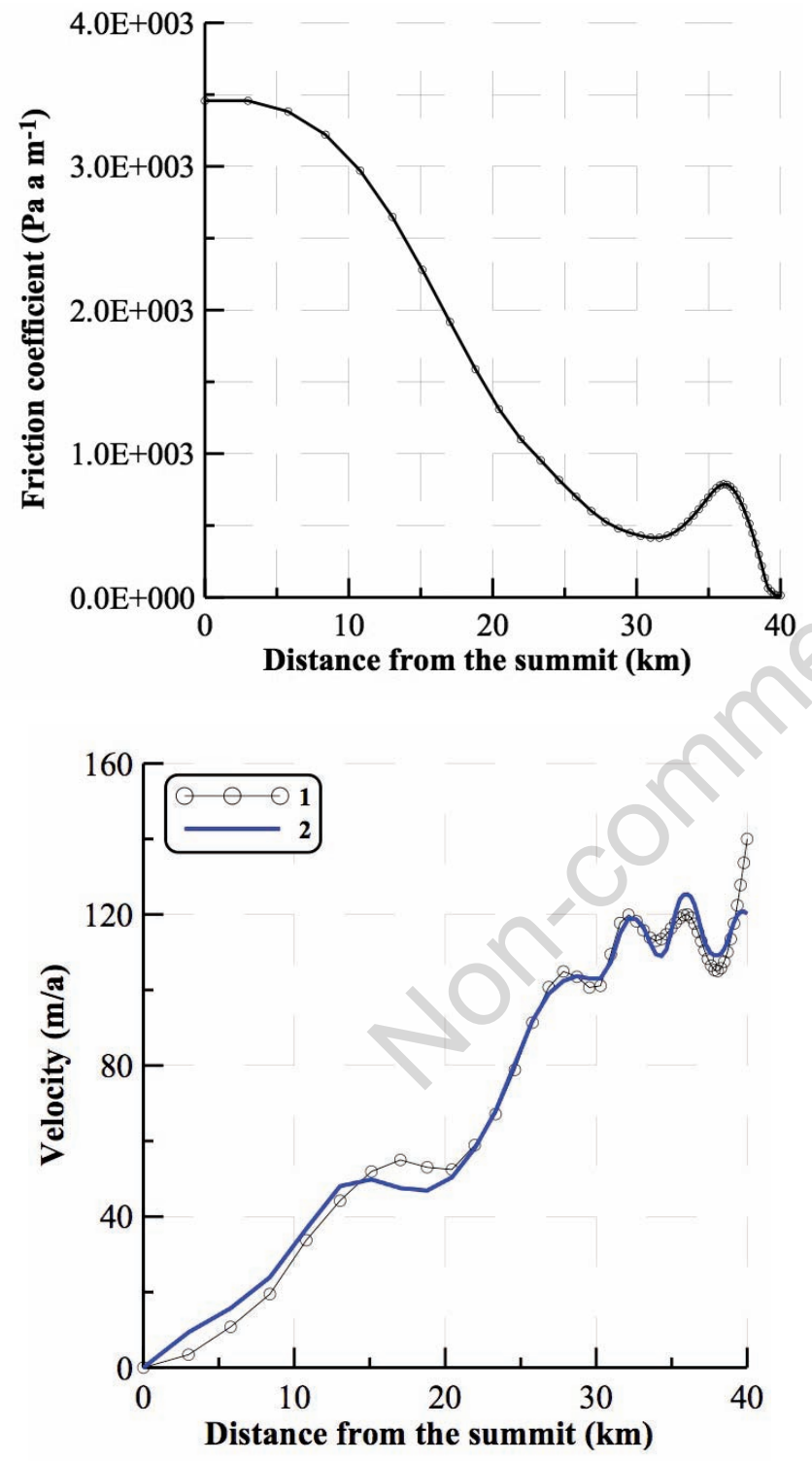

Figure 9. (A) The friction coefficient distribution obtained in the inverse problem for the linear friction law and for the observed surface velocity distribution along the $C-C^{\prime}$ flow line. The observed surface velocity distribution was taken from Figure 11 of Dowdeswell et al. ${ }^{1}$ (B) The ice surface horizontal velocity distributions along the flow line: 1 - the observed surface velocity distribution, ${ }^{1} 2$ - the modeled surface velocity distribution, which corresponds to the reconstructed friction coefficient in Figure 9A.
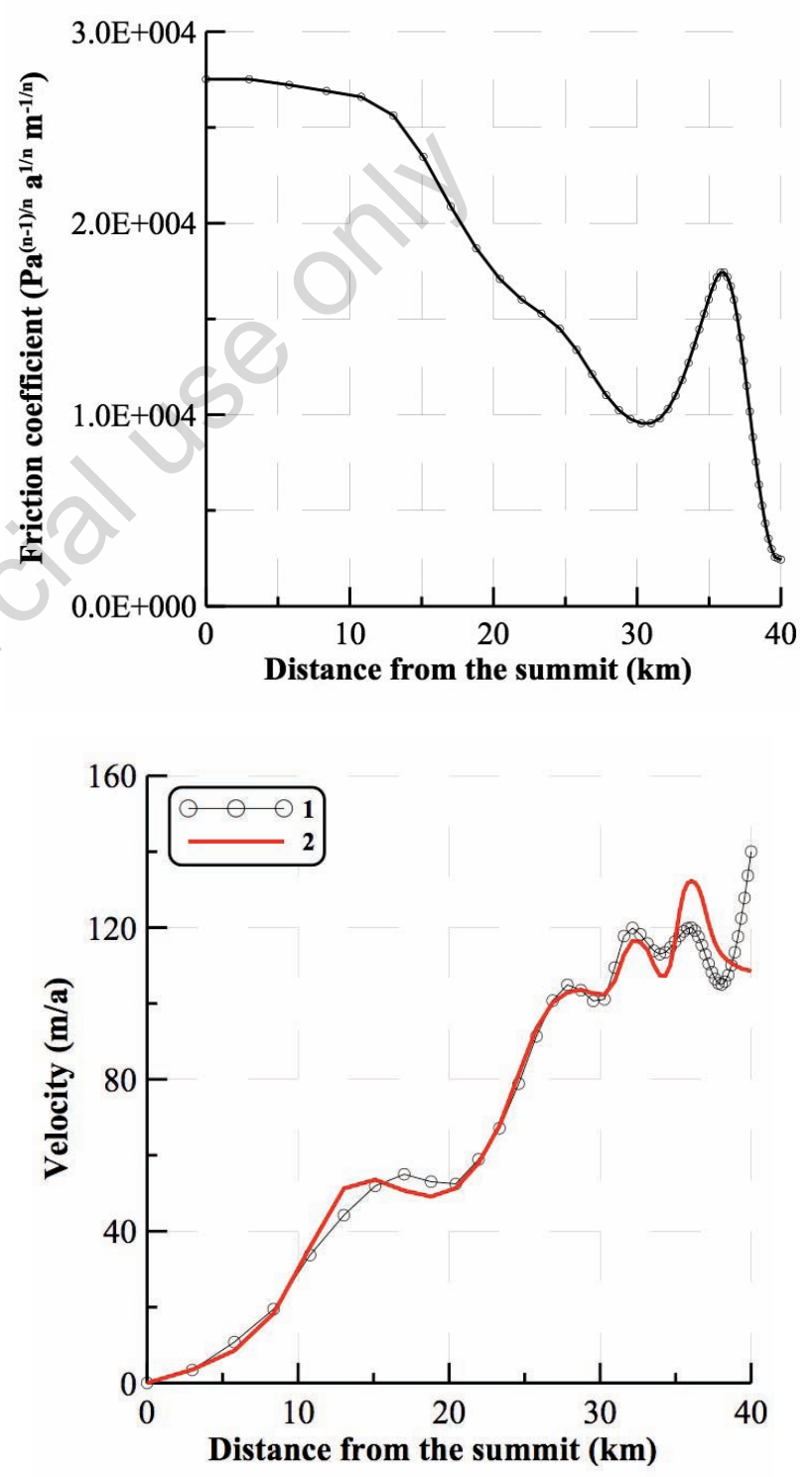

Figure 10. (A) The friction coefficient distribution obtained in the inverse problem for the non-linear Weertman type friction law and for the observed surface velocity distribution along the $C-C^{\prime}$ flow line (Figure 11 of Dowdeswell et al.1). (B) The ice surface horizontal velocity distributions along the flow line: 1 - the observed surface velocity distribution, ${ }^{1} 2$ - the modeled surface velocity distribution, which corresponds to the reconstructed friction coefficient in Figure 10A. 
ate equations include the basal pressure. ${ }^{2}$ Introduction of the hydrostatic pressure into Eq. (2) does not provide a constant value of the inverted friction coefficient at $x>25 \mathrm{~km}$. The inversion performed for the non-linear Weertman-type friction law reveals similar variations in the inverted friction coefficient at $x>25 \mathrm{~km}$ (Figure 10). The similar variability in the inverted friction coefficients obtained for both the linear (Figure 9A) and the non-linear (Figure 10A) friction laws implies that physical properties of the basal layer change according to the friction coefficient distribution along the flow line. In particular, the water content in the basal layer can vary in agreement with the bed elevation changes and enhancement of water content at lower elevations provides a decrease in the friction coefficient in corresponding areas.

Finally, the two areas can be distinguished in the ice base, where basal ice is frozen to the bed $(0<x<20 \mathrm{~km})$ and where there is basal sliding $(25<x<40 \mathrm{~km})$. The boundary of transition from the area of the frozen basal ice to the area of the basal sliding is diluted due to smoothing of the inverted friction coefficient by the stabilizer. The linear friction law provides good agreement between observed and modeled surface velocity distributions along the flow line.

\section{References}

1. Dowdeswell JA, Bassford RP, Gorman MR, et al. Form and flow of the Academy of Sciences Ice Cap, Severnaya Zemlya, Russian High Arctic. J Geophys Res 2002;107:1-15

2. Pattyn F. Ice-sheet modeling at different spatial resolutions: focus on the grounding zone. Ann Glaciol 2000;31:211-6.

3. Pattyn F. Transient glacier response with a higher-order numerical ice-flow model. J Glaciol 2002;48:467-77.

4. Colinge J, Blatter H. Stress and velocity fields in glaciers: Part I. Finite difference schemes for higher-order glacier models. J Glaciol 1998;44:448-56.

5. Sergienko OV, Bindschadler RA, Vornberger PL, MacAyeal DR. Ice stream basal conditions from block-wise surface data inversion and simple regression models of ice stream flow: Application to Bindschadler Ice Stream. J Geophys Res 2008;113:1-11.

6. Arthern R, Gudmundsson H. Initialization of ice-sheet forecasts viewed as an inverse Robin problem. J Glaciol 2010;56:527-33.

7. Gagliardini 0, Jay-Allemand M, Gillet-Chaulet, F. Friction distribution at the base of a surging glacier inferred from an inverse method. San Francisco, CA, USA: AGU Fall Meeting; 2010 Dec. 1317. Abstract: C13A-0540.

8. Habermann M, Maxwell DA, Truffer M. A principled stopping criterion for the reconstruction of basal properties in ice sheets. San Francisco, CA, USA: AGU Fall Meeting, 2010 Dec. 13-17. Abstract: C21C-0556.

9. Morlighem M, Rignot E, Seroussi H, et al. Spatial patterns of basal drag inferred using control methods from a full-Stokes and simpler models for Pine Island Glacier, West Antarctica. Geophys Res Lett 2010;37:1-6.

10. Jay-Allemand M, Gillet-Chaulet F, Gagliardini 0, Nodet M. Investigating changes in basal conditions of Variegated Glacier prior to and during its 1982-1983 surge. Cryosphere 2011;5:659-72.

11. Larour E, Seroussi H, Morlighem M, Rignot E. Continental scale, high order, high spatial resolution, ice sheet modeling using the Ice Sheet System Model (ISSM). J Geophys Res 2012;117:1-20.

12. Tikhonov AN, Arsenin VIa. Solutions of ill posed problems. Washington: Winston \& Sons; 1977.
13. Paterson WSB. The physics of glaciers. 3rd ed. Oxford: Pergamon Press; 1994.

14. Cuffey K, Paterson WSB. The physics of glaciers. 4th ed. Elsevier; 2010.

15. MacAyeal DR. Large-scale ice flow over a viscous basal sediment: theory and application to ice stream B, Antarctica. J Geophys Res 1989;94:4071-88.

16. MacAyeal DR. The basal stress-distribution of Ice Stream-E, Antarctica, inferred by control methods. J Geophys Res Solid Earth 1992;97:595-603.

17. Van der Veen CJ. Longitudinal stresses and basal sliding: a comparative study. In: Van der Veen CJ, Oerlemans J, (eds). Dynamics of the West Antarctic ice sheet. Dordrecht: D. Reidel Publishing Co.; 1987. pp 223-248.

18. Gudmundsson GH. Ice-stream response to ocean tides and the form of the basal sliding law. Cryosphere 2011;5:259-70.

19. Hindmarsh RCA, Hutter K. Numerical fixed domain mapping solution of free surface flows coupled with an evolving interior field. Int J Numer Anal Methods Geomech 1988;12:437-59.

20. Blatter H. Velocity and stress fields in grounded glaciers: a simple algorithm for including deviatoric stress gradients. J Glaciol 1995;41:333-44.

21. Hindmarsh RCA, Payne AJ. Time-step limits for stable solutions of the ice sheet equation. Ann Glaciol 1996;23:74-85.

22. Blatter H, Clarke GKC, Colinge J. Stress and velocity fields in glaciers: Part II. Sliding and basal stress distribution. J Glaciol 1998;44:457-66.

23. Pattyn F. A new three-dimensional higher-order thermomechanical ice sheet model. Basic sensitivity, ice stream development, and ice flow across subglacial lakes. J Geophys Res 2003;108:1-15.

24. Konovalov YV, Nagornov OV. The Gregoriev Ice Cap length changes derived by 2-D ice flow line model for harmonic climate histories. Solid Earth Discuss 2009;1:55-91.

25. Konovalov YV. Ice shelf flexures modeled with a 2D elastic flow line model. Cryosphere Discuss 2011;5:2841-63.

26. Nagornov OV, Konovalov YuV, Tchijov V. Temperature reconstruction for Arctic glaciers. Palaeogeogr Palaeoclimatol Palaeoecol 2006;236:125-34.

27. Benn DI, Hulton RJ, Mottram RH. Calving laws, sliding laws and the stability of tidewater glaciers. Ann Glaciol 2007;46:123-30.

28. Bassis JN, Fricker HA, Coleman R, Minster J-B. An investigation into the forces that drive ice-shelf rift propagation on the Amery Ice Shelf, East Antarcyica. J Glaciol 2008;54:17-27.

29. MacAyeal DR, Okal EA, Aster RC, et al. Transoceanic wave propagation links iceberg calving margins of Antarctica with storms in tropics and Northern Hemisphere. Geophys Res Lett 2006;33:1-4.

30. Bartholomaus TC, Larsen CF, O'Neel S, West ME. Ice quake source mechanisms explored with paired imagery and seismograms. San Francisco, CA, USA: AGU Fall Meeting; 2010 Dec. 13-17. Abstract: C52A-07.

31. Sugiyama S, Skvarca P, Naito N, et al. Calving glacier dynamics controlled by small fluctuations in subglacial water pressure revealed by hot water drilling in Glaciar Perito Moreno, Patagonia. San Francisco, CA, USA: AGU Fall Meeting; 2010 Dec. 13-17. Abstract: C11B-08.

32. Leonov AS. Some a posteriori termination rules for the iterative solution of linear ill-posed problems. Comput Math Math Phys 1994;34:121-6. 